\title{
« La conquête ottomane de la région de Diyarbakr au début du seizième siècle » (en japonais). Shigaku-Zasshi, CIX-8 (2000).
}

\section{Masahi Haneda}

\section{(2) OpenEdition}

Journals

Édition électronique

URL : http://journals.openedition.org/abstractairanica/35423

DOI : 10.4000/abstractairanica.35423

ISSN : 1961-960X

Éditeur :

CNRS (UMR 7528 Mondes iraniens et indiens), Éditions de l'IFRI

\section{Édition imprimée}

Date de publication : 15 mai 2002

ISSN : 0240-8910

Référence électronique

Masahi Haneda, " "La conquête ottomane de la région de Diyarbakr au début du seizième siècle » (en japonais). Shigaku-Zasshi, CIX-8 (2000). », Abstracta Iranica [En ligne], Volume 23 | 2002, document 164 mis en ligne le 08 février 2010, consulté le 25 septembre 2020. URL : http://journals.openedition.org/ abstractairanica/35423 ; DOI : https://doi.org/10.4000/abstractairanica.35423

Ce document a été généré automatiquement le 25 septembre 2020.

Tous droits réservés 


\title{
« La conquête ottomane de la région de Diyarbakr au début du seizième siècle » (en japonais). Shigaku- Zasshi, CIX-8 (2000).
}

\author{
Masahi Haneda
}

En utilisant deux sources fondamentales sur la situation politique du Kurdistan dans la première moitié du $16^{\mathrm{e}} \mathrm{s}$. (Selīm-nāme et Šaraf-nāme, tous deux en persan), Saito décrit, de manière détaillée, le processus de la conquête de cette région par les troupes ottomanes. Elle compare la structure administrative imposée par les Ottomans avec celle des Safavides et analyse les raisons du succès ottoman. Selon elle, alors que les Safavides ont essayé de régner sur la région par eux-mêmes en écartant les émirs kurdes et en les remplaçant par les émirs qizilbash, les Ottomans se sont contentés de contrôler la région indirectement et, dans une certaine mesure, ont laissé aux émirs kurdes leur terre d'origine.

\section{INDEX}

Thèmes : 4.2.1. Safavides et Qâjârs 


\section{AUTEURS}

\section{MASAHI HANEDA}

Institute of oriental culture (Université de Tokyo) 